\title{
Graphene quantum dots: structural integrity and oxygen functional groups for high sulfur/sulfide utilization in lithium sulfur batteries
}

\author{
Jungjin Park ${ }^{1,2,13}$, Joonhee Moon ${ }^{3,13}$, Chunjoong Kim ${ }^{4,13}$, Jin Hyoun Kang ${ }^{3}$, Eunhak Lim ${ }^{3}$, Jaesung Park ${ }^{5}$, \\ Kyung Jae Lee ${ }^{1,2}$, Seung-Ho Yu ${ }^{1,2}$, Jung-Hye Seo ${ }^{6,7}$, Jouhahn $\mathrm{Lee}^{6}$, Jiyoung Heo ${ }^{8}$, Nobuo Tanaka ${ }^{9}$, \\ Sung-Pyo Cho ${ }^{10}$, Jeffrey Pyun ${ }^{11}$, Jordi Cabana ${ }^{12}$, Byung Hee Hong ${ }^{3}$ and Yung-Eun Sung ${ }^{1,2}$
}

\begin{abstract}
Lithium-sulfur (Li-S) batteries are expected to overcome the limit of current energy storage devices by delivering high specific energy with low material cost. However, the potential of Li-S batteries has not yet been realized because of several technical barriers. Poor electrochemical performance is mainly attributed to the low electrical conductivity of the fully charged and discharged species, the irreversible loss of polysulfide anions and the decrease in the number of electrochemically active reaction sites during battery operation. Here, we report that the introduction of graphene quantum dots (GQDs) into the sulfur cathode dramatically enhanced sulfur/sulfide utilization, yielding high performance. In addition, the GQDs induced structural integrity of the sulfur-carbon electrode composite by oxygen-rich functional groups. This hierarchical architecture enabled fast charge transfer while minimizing the loss of lithium polysulfides, which is attributed to the physicochemical properties of GQDs. The mechanisms through which excellent cycling and rate performance are achieved were thoroughly studied by analyzing capacity versus voltage profiles. Furthermore, experimental observations and theoretical calculations further clarified the role played by GQDs by proving that C-S bonding occurs. Thus, the introduction of GQDs into Li-S batteries will provide an important breakthrough allowing their use as high-performance and low-cost batteries for next-generation energy storage systems. NPG Asia Materials (2016) 8, e272; doi:10.1038/am.2016.61; published online 20 May 2016
\end{abstract}

\section{INTRODUCTION}

Rechargeable lithium-ion batteries are widely used in various applications, such as portable devices, bio-medical implants and electric vehicles, because of their high energy and power density. ${ }^{1,2}$ However, current lithium-ion batteries based on the graphite and transition metal oxide couple have nearly reached their ceiling with respect to storage capability because of the limitations associated with their electrical properties and crystal structure. Therefore, breakthroughs in new energy storage systems that can surpass the current performance barrier of lithium-ion batteries should be brought about in a timely manner. Recently, Li-S batteries that can operate by the reversible electrochemical transformation between sulfur $\left(\mathrm{S}_{8}\right)$ and dilithium sulfide $\left(\mathrm{Li}_{2} \mathrm{~S}\right)$ have attracted great attention because they can deliver high energy with a moderate voltage owing to the direct use of elemental lithium and sulfur as an anode and a cathode, respectively. ${ }^{3}$ Sulfur generated from petroleum refinement is an ideal choice for a cathode owing to its low cost, environmental friendliness, and high theoretical specific capacity ( $1675 \mathrm{mAh} \mathrm{g}^{-1}$ by 16 electron process) when it is fully reduced to $\mathrm{Li}_{2} \mathrm{~S}^{2-4}$ However, several barriers limit the efficient use of sulfur as a cathode: the deleterious electrochemically induced volume expansion from $\mathrm{S}_{8}$ to $\mathrm{Li}_{2} \mathrm{~S}(\sim 80 \%)$, the poor electronic conductivities of $\mathrm{S}_{8}\left(\sim 1 \times 10^{-30} \mathrm{~S} \mathrm{~m}^{-1}\right)$ and $\mathrm{Li}_{2} \mathrm{~S}$ $\left(\sim 1 \times 10^{-14} \mathrm{~S} \mathrm{~m}^{-1}\right)$, and the irreversible loss of high-order polysulfides (HOPSs) to the electrolyte. ${ }^{5,6}$ In particular, the loss of HOPSs during cycling is responsible for poor cycle stability, low sulfur utilization and the polysulfide-shuttle phenomenon. ${ }^{3}$ To overcome this issue, various carbonaceous materials have been integrated into the sulfur cathode matrix to take advantage of their high electronic

\footnotetext{
${ }^{1}$ School of Chemical and Biological Engineering, Seoul National University, Seoul, Republic of Korea; ${ }^{2}$ Center for Nanoparticle Research, Institute for Basic Science, Seoul, Republic of Korea; ${ }^{3}$ Department of Chemistry, College of Natural Science, Seoul National University, Seoul, Republic of Korea; ${ }^{4}$ School of Materials Science and Engineering, Chungnam National University, Daejeon, Republic of Korea; ${ }^{5}$ Korea Research Institute of Standards and Science, Daejeon, Republic of Korea; ${ }^{6}$ Korea Basic Science Institute, Daejeon, Republic of Korea; ${ }^{7}$ Yonsei Center for Research Facilities, Seoul, Republic of Korea; ${ }^{8}$ Department of Biomedical Technology, Sangmyung University, Chungnam, Republic of Korea; ${ }^{9}$ EcoTopia Science Institute, Nagoya University, Nagoya, Japan; ${ }^{10}$ National Center for Inter-University Research Facilities, Seoul National University 1 Gwank-ro Gwanak-gu, Seoul, Republic of Korea; ${ }^{11}$ Department of Chemistry and Biochemistry, University of Arizona, Tucson, AZ, USA and ${ }^{12}$ Department of Chemistry, University of Illinois at Chicago, Chicago, IL, USA

${ }^{13}$ These authors contributed equally to this work.

Correspondence: Professor BH Hong, Department of Chemistry, College of Natural Science, Seoul National University, Seoul 151-747, Republic of Korea.

E-mail: byunghee@snu.ac.kr

or Professor Y-E Sung, School of Chemical and Biological Engineering, Seoul National University, Republic of Korea and Center for Nanoparticle Research, Institute for Basic Science, Seoul 151-742, Republic of Korea.

E-mail: ysung@snu.ac.kr

Received 14 December 2015; revised 29 February 2016; accepted 6 March 2016
} 
conductivity as well as their physicochemical properties to prevent HOPS dissolution into the electrolyte. ${ }^{7-11}$ Among many carbonaceous materials, graphene oxide-sulfur composites have been intensively reported as a novel material for preventing the loss of HOPSs through the adsorption and wrapping properties of graphene oxide. ${ }^{12-16}$ Despite significantly enhancing the electrochemical stability, these systems can be further improved by exhibiting better structural integrity. ${ }^{17}$ In previous studies, both the $S$ and graphene oxide used in batteries were reported to measure on the order of several micrometers; thus, conformal contact between graphene oxide and S is difficult to achieve, allowing HOPSs to be lost by repeated electrochemical cycling.

Recently, graphene particles measuring a few nanometers, graphene quantum dots (GQDs), were successfully synthesized; these particles were shown to demonstrate the quantum confinement effect, resulting in tunable electronic and optical properties. ${ }^{18,19}$ Interestingly, GQDs are enriched with oxygen functional groups on their edges, whereby unique properties such as a non-zero bandgap and luminescence on excitation have been reported. ${ }^{20-22}$ Furthermore, it is expected that GQDs can uniformly cover the target material due to their small size. Indeed, GQDs have been reported to serve as a composite member or coating material for energy storage devices. ${ }^{23,24}$

The current study is the first to introduce a GQDs-sulfur composite in a Li-S battery. Nano-sized GQDs (an average particle size of $\sim 4 \mathrm{~nm}$ ) enriched in oxygen functional groups could enhance the structural integrity of a conventional micron-sized sulfur-carbon electrode composite, forming a tightly packed structure. This hierarchical architecture facilitated charge conduction while minimizing the irreversible loss of HOPSs, thus enabling high sulfur/sulfide utilization even at a high current density. To study the mechanism through which enhanced electrochemical performance is achieved, careful analyses of capacity versus voltage profiles were carried out. Furthermore, we observed that the oxygen functional groups of GQDs help preserve dissolved HOPSs by the formation of C-S bonds (the so-called sulfiphilic property), as corroborated by various analytical tools and density functional theory (DFT) calculations. We believe that our results provide a new avenue for material scientists to make the best use of oxygen-rich functional groups in nano-sized carbon for various applications.

\section{EXPERIMENTAL PROCEDURES}

\section{Synthesis of graphene quantum dots}

GQDs were synthesized using a modified Hummer's method. Carbon fibers were placed into a mixture of $\mathrm{H}_{2} \mathrm{SO}_{4}$ and $\mathrm{HNO}_{3}$. The solution was sonicated for $2 \mathrm{~h}$ and then stirred for $24 \mathrm{~h}$. The solution was subsequently refluxed at $90{ }^{\circ} \mathrm{C}$ for $48 \mathrm{~h}$ under vigorous stirring. The resultant mixture was cooled to room temperature and diluted with deionized water, and the $\mathrm{pH}$ was adjusted to 8 with $\mathrm{Na}_{2} \mathrm{CO}_{3}$. The final product was dialyzed for 5 days and then filtered. Finally, the aqueous solution of GQDs was concentrated.

\section{Synthesis of GQDs-S/carbon black (CB) composites}

In $250 \mathrm{ml}$ deionized water, $1.5 \mathrm{~g}$ of sodium thiosulfate $\left(\mathrm{Na}_{2} \mathrm{~S}_{2} \mathrm{O}_{3}\right)$ powder as the precursor (Sigma Aldrich Corp., St Louis, MO, USA) was dissolved and then stirred while adding hydrochloric acid to obtain sulfur powders by chemical reduction. After the precipitation of sulfur, $1.0 \mathrm{vol} \%$ of a Triton X-100 aqueous solution $(15 \mathrm{ml})$ and the $80 \mathrm{mg}$ of the synthesized GQDs $\left(4 \mathrm{mg} \mathrm{ml}^{-1}\right)$ were sequentially added into the solution, followed by heating at $\sim 70^{\circ} \mathrm{C}$. The solution was again vigorously stirred for $20 \mathrm{~min}$, whereby a GQDs-S composite could be prepared. A carbon black (CB) suspension was then added to this GQDs-S suspension and was stirred for another $20 \mathrm{~min}$. Then, the solution was cooled to room temperature, and the collected products were rinsed several times using deionized water. Finally, GQDs-S/CB composites could be obtained by drying under vacuum.

\section{Cell fabrication and electrochemical measurements}

The electrodes were fabricated from slurries that contained $60 \mathrm{wt} \%$ sulfur, $20 \mathrm{wt} \% \mathrm{CB}$ as a conducting agent and $20 \mathrm{wt} \%$ polyvinylidene fluoride binder dispersed in N-methyl-2-pyrrolidone $(2 \mathrm{ml})$. The prepared slurry was cast onto aluminum foil using a doctor blade. The prepared electrodes were transferred to an Ar-filled glove box and were assembled into a 2032-type coin cell. The mass loading of all samples was $\sim 1.0$ or $\sim 2.2 \mathrm{mg} \mathrm{cm}^{-2}$ of active material. An electrolyte containing $1.0 \mathrm{M}$ LiTFSI (lithium bis-trifluoromethanesulfonimide) and $0.1 \mathrm{M} \mathrm{LiNO}_{3}$ (lithium nitrate) with dioxolane and dimethyl ether in a 1:1 volume ratio (Panax Etec, Busan, Republic of Korea) was prepared and used in each sample at a volume of $40 \mu$ l. The polymeric separator used in the samples was supplied by SK Innovation (Republic of Korea), and lithium metal was used as a counter electrode. Electrochemical properties were measured with a WBCS3000 cycler (Won-A Tech, Seoul, Republic of Korea). The voltage window for the electrochemical measurements was set to $1.5-3.0 \mathrm{~V}$ versus $\mathrm{Li}$ +/Li (all the voltages below are referenced by redox potential of $\mathrm{Li}_{1} \mathrm{Li}^{+} / \mathrm{Li}$ ). CB and GQDs/CB (the mixture of CB and GQDs, 1:1 weight ratio) electrodes were fabricated similarly to the aforementioned procedures from slurries that contained $80 \mathrm{wt} \% \mathrm{CB}$ and GQDs/CB, and $20 \mathrm{wt} \%$ polyvinylidene fluoride binder dispersed in N-methyl-2-pyrrolidone $(2 \mathrm{ml})$.

$\mathrm{Li}_{2} \mathrm{~S}_{8}$ catholyte was prepared using $\mathrm{Li}_{2} \mathrm{~S}$ and $\mathrm{S}_{8}$ powders (Sigma Aldrich Corp., USA), which were added to 1.0 M LiTFSI (lithium bis-trifluoromethanesulfonimide) and $0.1 \mathrm{M} \mathrm{LiNO}_{3}$ (lithium nitrate) with dioxolane and dimethyl ether in a 1:1 volume ratio (Panax Etec, Republic of Korea). After cycle operation, the coin cells were disassembled in an Ar-filled glove box and thoroughly rinsed with copious amounts of DOL/dimethyl ether before analysis. Electrochemical impedance spectroscopy measurements were performed at an open-circuit potential between 100 and $100 \mathrm{mHz}$ with fluctuations of $<10 \mathrm{mV}$, and the resulting Nyquist plots were fitted based on the equivalent circuits.

\section{Characterization techniques}

X-ray diffraction (XRD) was performed on a Smartlab diffractometer (Rigaku) equipped with a rotating anode and a $\mathrm{Cu} \mathrm{K} a$ radiation source $\left(\lambda_{\mathrm{avg}}=1.5418 \AA\right)$ at $45 \mathrm{kV}$ and $200 \mathrm{~mA}$. Transmission electron microscopy (TEM) was performed on a JEOL JEM-2100 F (JEOL, Japan). Scanning TEM, energy dispersive X-ray spectroscopy (EDS) and electron energy loss spectroscopy mapping were carried out with a Tecnai F20 (FEI) equipped with an EDAX Tecnai 136-5 detector. Scanning electron microscopy (SEM) was performed using a SUPRA 55VP FE-SEM (Carl Zeiss). X-ray photoelectron spectroscopy (XPS) was performed on an AXIS Ultra DLD (Kratos Inc.) using a 150-W monochromatic Al Ka $(1486.6 \mathrm{eV}) \mathrm{X}$-ray source at the Korea Basic Science Institute. High-resolution XPS data were collected over a pass energy of $40 \mathrm{eV}$ in $0.05 \mathrm{eV}$ steps. XPS data were fitted using XPS Peak41 software. Raman spectra were obtained using a micro-Raman spectrometer (Renishaw) with an excitation wavelength of $514.5 \mathrm{~nm}$. The diameter of the beam spot was $\sim 1 \mu \mathrm{m}$. Fourier transform infrared spectra were obtained by a Nicolet 6700 (Thermo Scientific, Waltham, MA, USA).

\section{Computational methods}

DFT calculations were carried out to optimize structures and analyze frequencies. The conventional B3LYP exchange-correlation functional was used for the DFT calculations. B3LYP is a hybrid-GGA exchange-correlation functional, which means the size-consistency problem cannot be considered. ${ }^{25}$ To more precisely describe the anion systems, we used a 6-31+ $+\mathrm{G}(\mathrm{d})$ basis set, which added diffuse functions to all atoms. All structures reported in this paper were optimized, as confirmed by frequency analysis. The GAUSSIAN 09 package was used for all calculations. ${ }^{26}$

\section{RESULTS AND DISCUSSION}

\section{Material characterization}

Characterization of GQDs. Various microscopic and spectroscopic analytical tools were employed to study the physical/chemical 

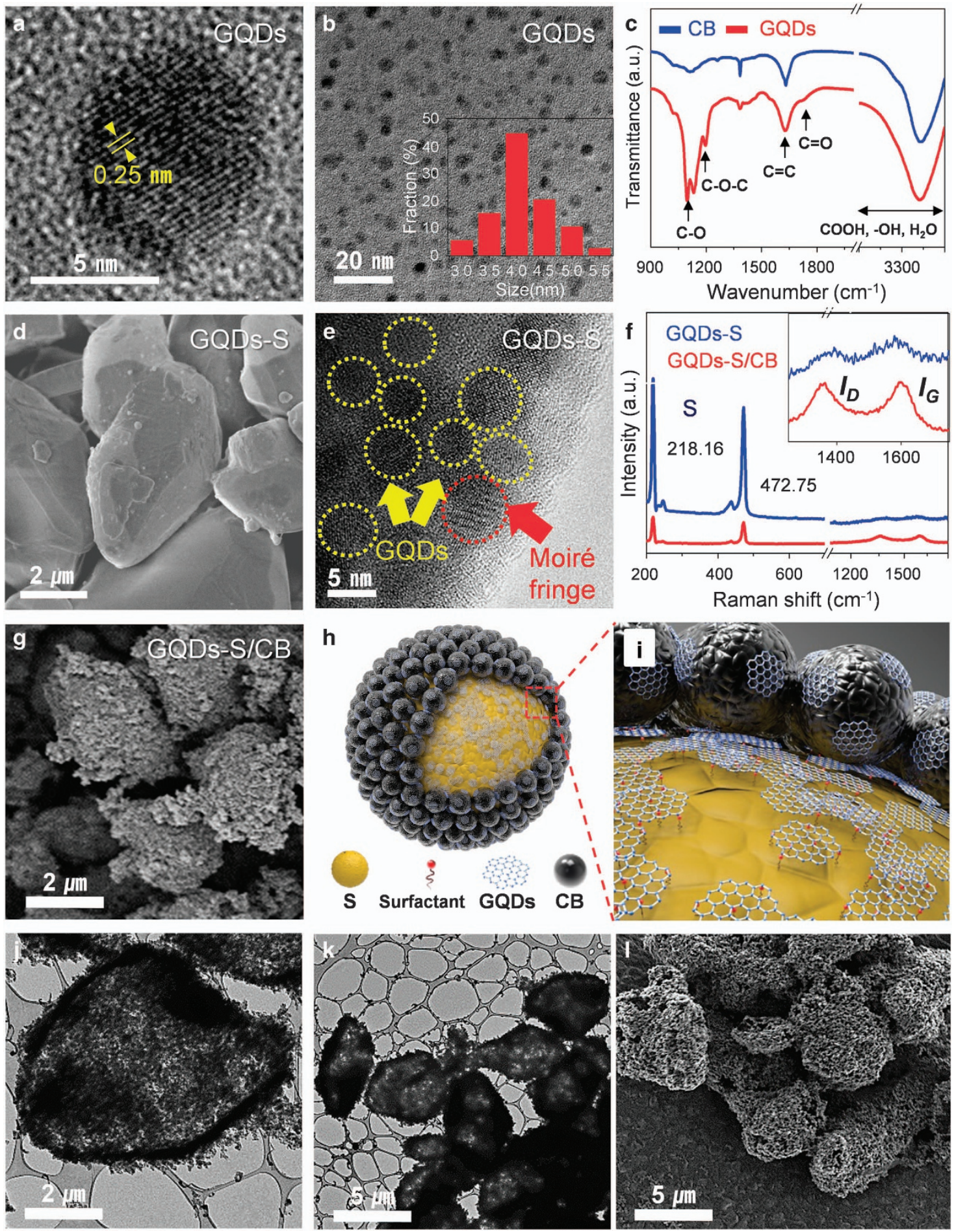

Figure 1 Materials characterization of GQDs-S/CB and S/CB composites. (a, b) High-resolution TEM images of GQDs; the inset shows a histogram of the GQD size distribution. (c) FT-IR spectra of GQDs and CB. The peaks in this figure correspond to the various functional groups in the GQDs and CB. SEM images of (d) GQDs-S and (g) GQDs-S/CB. (e) High-resolution transmission electron microscope (HRTEM) images of the GQDs-S composites and GQD pattern (yellow circle). A Moiré pattern (red circle) is clearly visible in these TEM images, which was created by a superposition of the GQDs and $S$ crystalline lattices. (f) Raman spectra of GQDs-S and GQDs-S/CB composites, which show that the GQDs were formed on the sulfur particles. The strong peaks at 218.16 and $472.75 \mathrm{~cm}^{-1}$ arise from sulfur, and the D (disorder) and G (graphitic) peaks arise from the GQDs. Schematic diagrams show (h) the structure and (i) the magnified structure of GQDs-S/CB. (j, k) HRTEM images, and (I) SEM image of the shell structures of GQDs-S/CB after rinsing with a $\mathrm{CS}_{2}$ solution.

properties of the GQDs. High-resolution transmission electron microscope images were collected to study the morphology of the GQDs (Figure 1a and b). The GQDs were highly crystalline, showing an average size of $4.11 \mathrm{~nm}( \pm 0.55$; the inset of Figure 1b). Oxygen-rich functional groups on the edge of the GQDs, where non-bonding carbons exist, were identified by Fourier transform infrared 
a

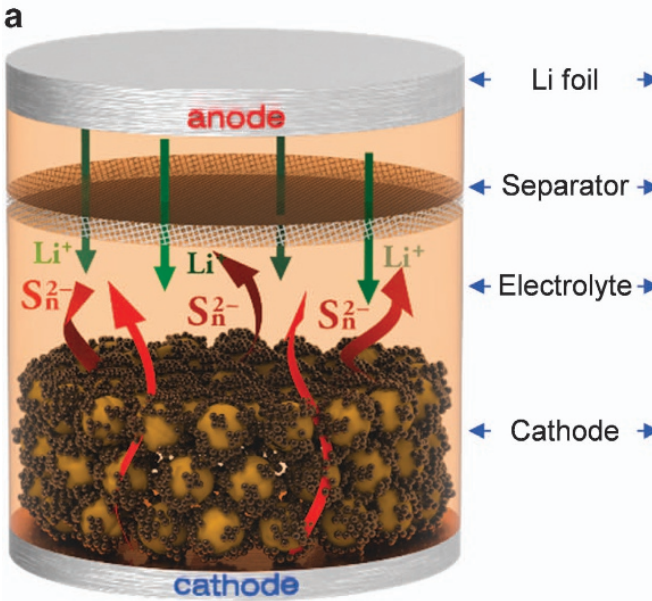

b

b

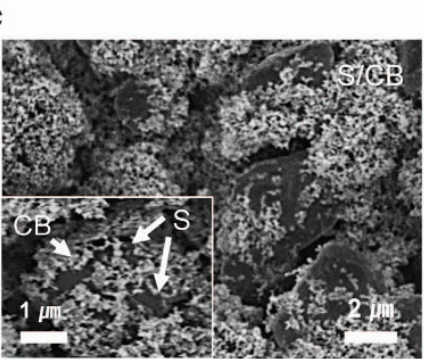

d

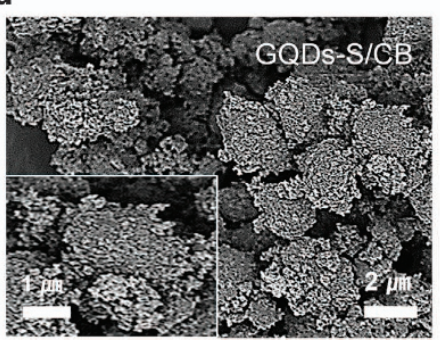

Figure 2 Schematic diagrams and SEM images of S/CB and GQDs-S/CB in a Li-S battery. (a, b) Schematic configuration of S/CB and GQDs-S/CB employed as a cathode in a Li-S battery. The sulfur (yellow) was wrapped with $\mathrm{CB}$ (S/CB) and compactly covered with GQDs and CB (GQDs-S/CB). Polysulfides were dissolved into the solvent and the color changed to orange. (c, d) SEM images of GQDs-S/CB and S/CB.

spectroscopy (Figure 1c). Strong peaks attributed to the characteristic vibrational modes of oxygen functional groups $\left(-\mathrm{OH}\right.$ at $3434 \mathrm{~cm}^{-1}$, $\mathrm{C}=\mathrm{O}$ at $1725 \mathrm{~cm}^{-1}, \mathrm{C}-\mathrm{O}$ in $1024-1180 \mathrm{~cm}^{-1}$ and $\mathrm{C}-\mathrm{O}-\mathrm{C}$ at $1200 \mathrm{~cm}^{-1}$ ) could be clearly observed in the spectra of the GQDs, whereas the peak at $1629 \mathrm{~cm}^{-1}$ resulted from $\mathrm{sp}^{2}$-hybridized $\mathrm{C}=\mathrm{C}$ bonds (in-plane stretching). ${ }^{27}$

Characterization of the GQDs-S composite. The SEM and TEM images in Figure 1d and e show the morphology of the GQDs-S. Sulfur particles measuring several microns were homogeneously coated with GQDs. The uniform distribution of GQDs on the sulfur surface was confirmed by EDS mapping of C, O and S (Supplementary Figure S1). Such a uniform distribution of GQDs could be achieved because of the small size of the GQDs as well as the oxygen functional groups on the particles, which led to electrostatic interactions with sulfur. The graphitic characteristic of GQDs-S was analyzed by Raman spectroscopy (Figure 1f); the peaks for carbon (D and G at 1350 and $1590 \mathrm{~cm}^{-1}$ ) and sulfur (the four characteristic peaks below $600 \mathrm{~cm}^{-1}$ ) could be clearly resolved in the spectra. ${ }^{28,29}$

Characterization of the GQDs-S/CB composite. GQDs-S/CB (average particle size of $\sim 50 \mathrm{~nm}$ ) composite structures were prepared from GQDs-S and CB via van der Waals interactions. ${ }^{12}$ The SEM image of the GQDs-S/CB composite shown in Figure $1 \mathrm{~g}$ indicates that CBs were tightly bound to the GQDs-S composites. Scanning TEM-EDS was performed to determine the compositional distribution of $\mathrm{C}, \mathrm{O}$ and $\mathrm{S}$ in the GQDs-S/CB composite, and the results show that $\mathrm{C}, \mathrm{O}$ and $\mathrm{S}$ were homogeneously distributed throughout the composite structure (Supplementary Figure S2). X-ray diffraction analysis of the GQDs-S/CB composite structures reveals high crystallinity and phase purity of sulfur (Supplementary Figure S3a). The composition of GQDs-S/CB was estimated by thermogravimetric analysis (Supplementary Figure S3b) to be 70:20:10 (wt\%) S:CB:GQD. XPS, the results of which are shown in Supplementary Figure S4, was performed to analyze the surface of the GQDs-S/CB composite; the results of the quantitative analysis are presented in Supplementary Table S1. The results indicate that a higher $\mathrm{C}=\mathrm{O}$ intensity $(286.7 \mathrm{eV}$ in $\mathrm{C} 1 \mathrm{~s}$ and $530.9 \mathrm{eV}$ in $\mathrm{O} 1 \mathrm{~s})$ and $\mathrm{C}-\mathrm{OH}(533.0 \mathrm{eV}$ in $\mathrm{O} 1 \mathrm{~s})$ was observed for GQDs-S/CB than for $\mathrm{S} / \mathrm{CB}$ because of the oxygen functional group of the GQDs. ${ }^{30}$ Moreover, a negligible S 2p signal was detected because the GQDs-S was well covered with $\mathrm{CB}$ in the GQDs-S/CB structure (see $\mathrm{S} 2 \mathrm{p}$ in GQDs-S/CB vs $\mathrm{S} / \mathrm{CB}$ ). The schematic illustrations in Figure $1 \mathrm{~h}$ and i show the GQDs distributed on a sulfur particle, which could strongly bond to $\mathrm{CB}$, leading to a densely packed GQDs-S/CB composite structure. To investigate the structural integrity and mechanical stability of the hierarchal structure, sulfur was dissolved by a $\mathrm{CS}_{2}$ solution from the GQDs-S/CB composite. Even without sulfur, the structure of the composite was well preserved, as shown in TEM and SEM images (Figure 1j-1).

Schematic Illustration of GQDs-S/CB in a Li-S Battery. The schematic illustration in Figure 2a depicts a conventional Li-S battery, in which the anode and the cathode are made of metallic lithium foil and the composite of sulfur and CB, respectively. The structure of the cathode has a great impact on the irreversible loss of HOPSs during repeated battery operation. In this study, GQDs were introduced into the S/CB cathode, as shown in Figure 2b. The GQDs contained both hydrophobic aromatic and hydrophilic defective regions, which could interact with $\mathrm{CBs}$ and sulfur, respectively. ${ }^{12}$ SEM images (Figure $2 \mathrm{c}$ and d) confirm that the GQDs-S/CB composite electrodes were 
a Specific capacity (mAh $\left.\mathrm{g}^{-1}\right)$

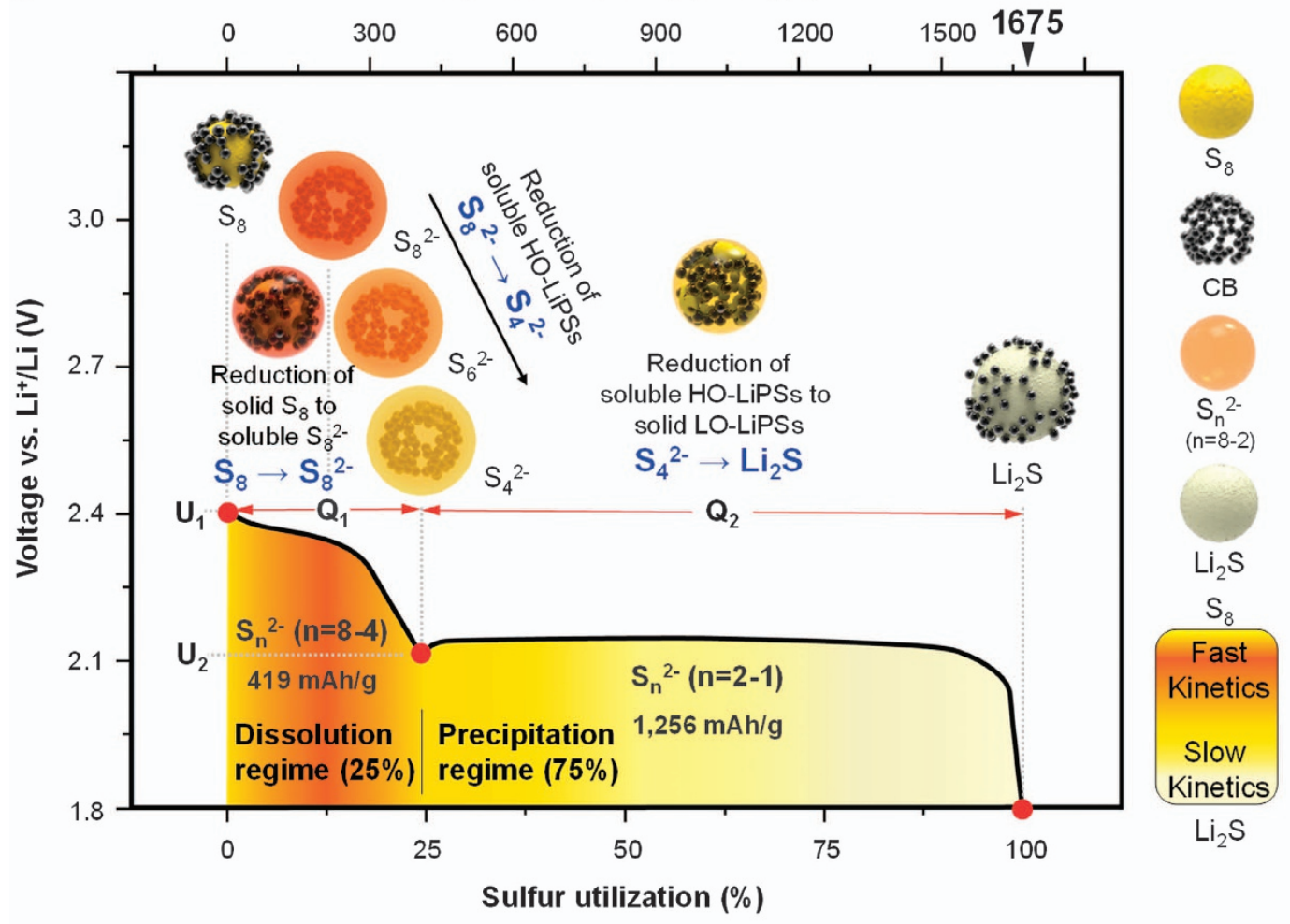

b
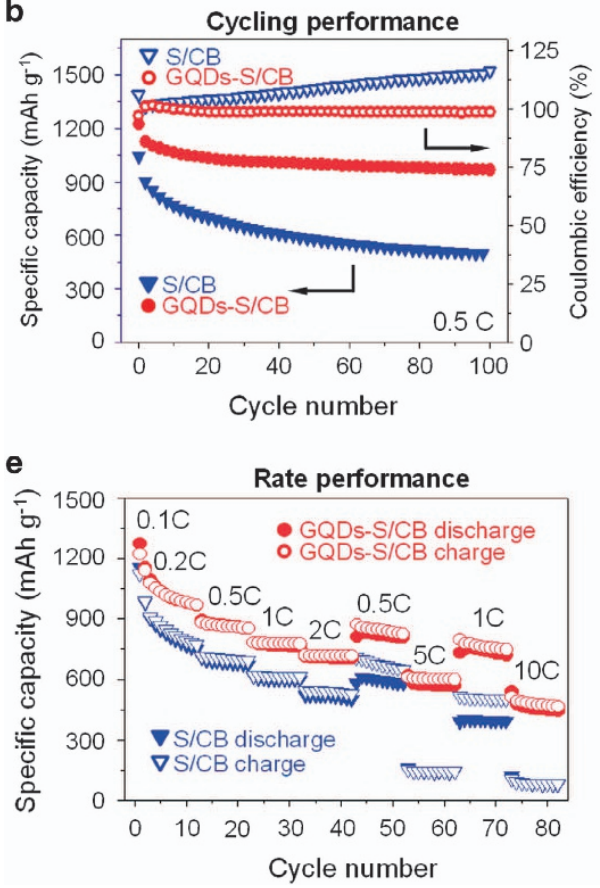

c

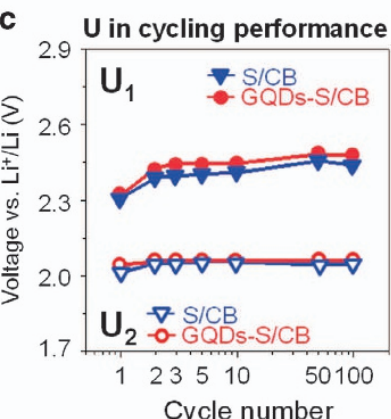

f

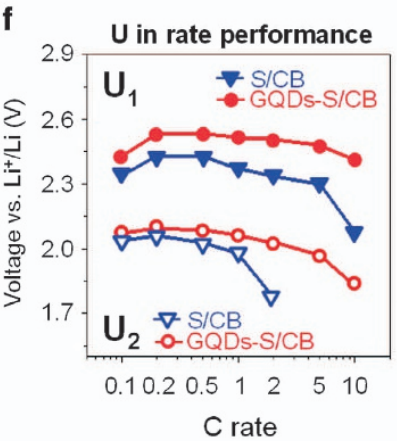

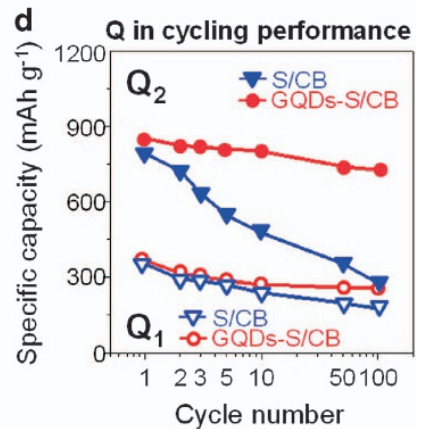

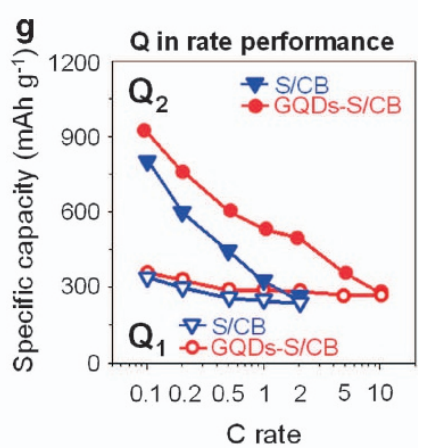

Figure 3 Electrochemical properties of S/CB and GQDs-S/CB electrodes. (a) Schematic illustration of the discharge profile of a conventional Li-S battery. HOPSs $\left(\mathrm{S}_{n}{ }^{2-}, n=8-4\right)$ and low-order polysulfides $\left(\mathrm{S}_{n}{ }^{2-}, n=2-1\right)$ are abbreviated as HO-PSs and LO-PSs, respectively. The onset potential (U) and the capacity $(\mathrm{Q})$ in the dissolution and precipitation regime are noted, which facilitates the analysis of the electrochemical properties of each sample. (b) The cycling performance and Coulombic efficiency of both samples at $0.5 \mathrm{C}$ over 100 cycles. (e) Rate performance of the GQDs-S/CB and S/CB at $0.1 \mathrm{C}$ to $10 \mathrm{C}$. (c, f) Onset potentials as a function of cycle number and (d, $\mathbf{g})$ capacities as a function of cycle number.

densely packed with $\mathrm{CBs}$, which should have enhanced the electrochemical performance by highly preserving HOPSs in the geometric structure of GQDs-S/CB, whereas the surface of the sulfur particles was partially exposed in the S/CB electrode.
Electrochemical tests for $\mathrm{Li}-\mathrm{S}$ batteries

Capacity versus voltage profile. The discharge profile in Figure 3a illustrates a schematic model of possible reaction pathways that occur in a conventional Li-S battery. In the upper plateau region at $\sim 2.3 \mathrm{~V}$, 
elemental sulfur, $S_{8}$, is gradually reduced to the soluble sulfide anion $\left(\mathrm{S}_{8}{ }^{2-}\right)$. Then, $\mathrm{S}_{8}{ }^{2-}$ is continuously reduced to $\mathrm{S}_{\mathrm{n}}{ }^{2-}(n=6$ and 4$){ }^{31}$ These HOPSs $\left(\mathrm{S}_{\mathrm{n}}{ }^{2-}, n=8-4\right)$ are generated and soluble in the electrolyte; thus, the summation of the upper plateau and slope regions between $\sim 2.3$ and $\sim 2.1 \mathrm{~V}$ can be defined as the dissolution region. Once the composition of $\mathrm{S}_{4}{ }^{2-}$ is reached, HOPSs are further reduced to low-order polysulfides (LOPSs, $\left(\mathrm{S}_{\mathrm{n}}{ }^{2-}, n=2\right.$ and 1$)$ ) in the lower plateau region $(\sim 2.1 \mathrm{~V})$, whereas HOPSs are soluble in the electrolyte, LOPSs are precipitated as solid phases. Thus, the lower plateau region can be defined as the precipitation region. Finally, $\mathrm{Li}_{2} \mathrm{~S}$ is formed by the complete reduction of $S_{8}$, leading to a theoretical capacity of $1675 \mathrm{mAh} \mathrm{g}^{-1}$. Representative points $\mathrm{U}_{1}, \mathrm{U}_{2}, \mathrm{Q}_{1}$ and $\mathrm{Q}_{2}$ are marked in the profile, Figure $3 a$, where $U_{1}$ and $U_{2}$ indicate the onset reaction potentials of the dissolved and precipitated species, respectively, whereas $\mathrm{Q}_{1}$ and $\mathrm{Q}_{2}$ are the capacities corresponding to the dissolution and precipitation regions, respectively. $\mathrm{Q}_{1}$ is estimated to be $419 \mathrm{mAh} \mathrm{g}^{-1}$ from the reaction $\mathrm{S}_{8}(\mathrm{~s})+4 \mathrm{Li}^{+}+4 \mathrm{e}^{-} \leftrightarrow 2 \mathrm{Li}_{2} \mathrm{~S}_{4}$ (l), whereas $Q_{2}$ is $1256 \mathrm{mAh} \mathrm{g}^{-1}$, which is achieved by the reduction of HOPSs to LOPSs, $2 \mathrm{Li}_{2} \mathrm{~S}_{4}(\mathrm{l})+12 \mathrm{Li}^{+} \leftrightarrow 8 \mathrm{Li}_{2} \mathrm{~S}$ (s). In this work, four representative parameters $\left(\mathrm{U}_{1}, \mathrm{U}_{2}, \mathrm{Q}_{1}\right.$ and $\left.\mathrm{Q}_{2}\right)$ and the $\mathrm{Q}_{2} / \mathrm{Q}_{1}$ ratio $(=3)$ were evaluated to understand the battery performance of GQDsS/CB composite electrodes. ${ }^{31}$

Cycling performance. The cycling performance of GQDs-S/CB was tested at a $0.5 \mathrm{C}$ rate $\left(1 \mathrm{C}=1675 \mathrm{mAh} \mathrm{g}^{-1}\right.$ assuming the reaction, $\mathrm{S}_{8}$ $\left.+16 \mathrm{Li}^{+}+16 \mathrm{e}^{-} \leftrightarrow 8 \mathrm{Li}_{2} \mathrm{~S}\right)$, as shown in Figure $3 \mathrm{~b}$. The GQDs-S/CB composites exhibited superior cyclability and stable Coulombic efficiency compared with S/CB. A discharge capacity of $\sim 1000 \mathrm{mAh} \mathrm{g}^{-1}$ was achieved even after 100 cycles, whereas S/CB showed a discharge capacity of only $459.6 \mathrm{mAh} \mathrm{g}^{-1}$. Capacity versus voltage profiles at selected cycles are presented in Supplementary Figure S5. The Coulombic efficiency of GQDs-S/CB remained stable at $\sim 100.0 \%$ for 100 cycles, whereas that of S/CB continued to increase and reached $\sim 110 \%$ at the 100 th cycle. The sustained increase in Coulombic efficiency is reported to be attributed to the polysulfideshuttle phenomenon. Therefore, it is understood that the electrochemically efficient architecture can be provided by GQDs-S/CB, which enables high utilization of active materials, that is, the reversible reaction of sulfur during the discharge process, as confirmed by the $\mathrm{Q}_{2} / \mathrm{Q}_{1}$ ratio.

The onset potentials $\left(\mathrm{U}_{1}\right.$ and $\left.\mathrm{U}_{2}\right)$ and the capacities $\left(\mathrm{Q}_{1}\right.$ and $\left.\mathrm{Q}_{2}\right)$ as a function of cycle number were derived from the capacity versus voltage profiles and are presented in Figure $3 \mathrm{c}$ and $\mathrm{d}$ to study the origin of the enhanced cycle performance of the GQDs-S/CB composite. The values of those parameters are also tabulated in Supplementary Tables S2. In the first cycle, $\mathrm{U}_{1}$ of GQDs-S/CB was $2.33 \mathrm{~V}$, which was slightly higher than that of $\mathrm{S} / \mathrm{CB}, 2.31 \mathrm{~V}$, owing to lower interface resistance. Lower interface resistance is attributed to faster electron transfer kinetics by better carbon coverage in GQDs-S/CB (Figure 3c). The interfacial resistance was further studied by electrochemical impedance spectroscopy, as shown in Supplementary Figure S6.

The radius of the semi-circle $(100 \mathrm{kHz}-1 \mathrm{~Hz})$ on the $\operatorname{Re}(\mathrm{Z}$; ohm $)$ axis is determined by the sum of the interfacial resistance and charge transfer resistance $\left(\mathrm{R}_{\mathrm{int}}+\mathrm{R}_{\mathrm{ct}}\right)$ based on the equivalent circuit in Supplementary Figure S6a, which indicates that the GQDs-S/CB electrode exhibited a lower complex (interfacial and charge transfer) resistance than the S-CB electrode. ${ }^{32}$ The $\mathrm{U}_{2}$ value of GQDs-S/CB was also slightly higher $(\Delta 30 \mathrm{mV})$ than that of $\mathrm{CB} / \mathrm{S}$, which indicates that HOPSs are more easily reduced to LOPSs. After the first cycle, a slight increase in $U_{1}$ and $U_{2}$ was observed for both electrodes because of the decrease in the overpotential resulting from the rearrangement of micron-sized sulfur. ${ }^{33}$ The $\mathrm{U}_{1}$ and $\mathrm{U}_{2}$ values of GQDs-S/CB were higher than those of S/CB over 100 cycles, which confirms that the GQDs-S/CB composite has relatively low resistance to the discharge process at each cycle. In contrast, $\mathrm{Q}_{1}$ and $\mathrm{Q}_{2}$ exhibit quite different behavior between GQDs-S/CB and S/CB, as shown in Figure 3d. For the first cycle, higher $\mathrm{Q}_{1}$ and $\mathrm{Q}_{2}$ value were observed in GQDs-S/CB $\quad\left(\mathrm{Q}_{1}=370.90 \mathrm{mAh} \mathrm{g}^{-1}\right.$ and $\left.\mathrm{Q}_{2}=853.24 \mathrm{mAh} \mathrm{g}^{-1}\right)$ compared with those observed in $\mathrm{S} / \mathrm{CB}\left(\mathrm{Q}_{1}=354.86 \mathrm{mAh} \mathrm{g}^{-1}\right.$ and $\mathrm{Q}_{2}=793.35 \mathrm{mAh} \mathrm{g}^{-1}$ ) because of the more efficient utilization of active materials by the introduction of GQDs. However, the $\mathrm{Q}_{2} / \mathrm{Q}_{1}$ ratios were still low in both the GQDs-S/CB $\left(\mathrm{Q}_{2} / \mathrm{Q}_{1}=2.30\right)$ and $\mathrm{S} / \mathrm{CB}$ $\left(\mathrm{Q}_{2} / \mathrm{Q}_{1}=2.24\right)$ samples. Such a low $\mathrm{Q}_{2} / \mathrm{Q}_{1}$ ratio for the first cycle can be ascribed to the irreversible initial loss of HOPSs and the inefficient precipitation of LOPSs. Afterward, the $\mathrm{Q}_{1}$ and $\mathrm{Q}_{2}$ values gradually decreased with extended cycling in S/CB. Notably, the $\mathrm{Q}_{1}$ values showed relatively slow decay, but severe fading of $\mathrm{Q}_{2}$ was observed, which indicates that the precipitation reaction was impeded by the loss of active sites. In contrast, the $\mathrm{Q}_{1}$ and $\mathrm{Q}_{2}$ values were maintained for GQDs-S/CB even after 100 cycles through a minimized loss of active species and preservation of active sites to facilitate reactions. The $\mathrm{Q}_{2} / \mathrm{Q}_{1}$ ratios in GQDs-S/CB were determined to be 2.94 and 2.81 at the 10th cycle and the 100th cycle, respectively, which are close to the theoretical value ( $=3$ ), whereas the $\mathrm{Q}_{2} / \mathrm{Q}_{1}$ ratios of $\mathrm{S} / \mathrm{CB}$ were 1.96 and 1.55 at the 10th and 100th cycles, respectively. Such high $\mathrm{Q}_{2} / \mathrm{Q}_{1}$ ratios strongly indicate that the redox reaction between $\mathrm{S}_{8}$ and $\mathrm{Li}_{2} \mathrm{~S}$ can occur very reversibly owing to the highly efficient electrode structure driven by the GQDs. The GQDs can aid in capturing the HOPSs during the electrochemical reaction, which will be discussed in detail later. In addition, the results of the electrochemical impedance spectroscopy study (Supplementary Figure S6b and c) and associated discussion supporting polysulfide (PS) capture by GQDs can are provided in the supplementary section. Even though an electrode with high sulfur loading was prepared $\left(\sim 2.2 \mathrm{mg} \mathrm{cm}^{-2}\right)$, GQDs-S/CB showed superior cycle performance $\left(\sim 950 \mathrm{mAhg}^{-1}\right)$ compared with that of S/CB $\left(\sim 280 \mathrm{mAh} \mathrm{g}^{-1}\right)$ (Supplementary Figure S7), which indicates higher cycle performance compared with that reported in previous studies of carbon/sulfur composites (Supplementary Table S4).

Rate capability. The rate capabilities of GQDs-S/CB and S/CB were tested from $0.1 \mathrm{C}$ to $10 \mathrm{C}$ and are presented in Figure $3 \mathrm{e}$ (see Supplementary Figure S8 for the capacity versus voltage profiles at the different rates). The GQDs-S/CB showed excellent rate capabilities compared with those of S/CB. Supplementary Figure S9 shows that a high discharge capacity of $540.17 \mathrm{mAh} \mathrm{g}^{-1}$ at $10 \mathrm{C}$ could be attained $(42 \%$ versus the discharge capacity at $\mathrm{C} / 10)$ in GQDs-S/CB. In contrast, a discharge capacity of only $120.35 \mathrm{mAh} \mathrm{g}^{-1}$ could be achieved at $10 \mathrm{C}(10 \%$ versus that at $\mathrm{C} / 10)$ in $\mathrm{S} / \mathrm{CB}$. This rate performance, even at the $10 \mathrm{C}$ rate, demonstrates the superior properties of the composite compared with those reported in previous studies in Supplementary Figure S10. To study the origin of such high rate capabilities in the GQDs-S/CB electrodes, the evolution of four parameters with the rate were investigated. The $\mathrm{U}_{1}$ and $\mathrm{U}_{2}$ values were derived from the rate capability tests, as shown in Figure $3 \mathrm{f}$. The GQDs-S/CB electrode showed slightly higher $\mathrm{U}_{1}$ and $\mathrm{U}_{2}$ values than those of $S / C B$ at a relatively low rate $(<0.2 \mathrm{C})$. However, the $\mathrm{U}_{1}$ and $\mathrm{U}_{2}$ values of the $\mathrm{S} / \mathrm{CB}$ electrodes decreased significantly at a rate above $0.5 \mathrm{C}$, whereas the $\mathrm{U}_{1}$ and $\mathrm{U}_{2}$ values of the GQDs-S/CB electrodes remained more stable. The higher $\mathrm{U}_{1}$ and $\mathrm{U}_{2}$ values in the GQDs-S/CB electrode confirm that the GQDs increase the electrical conductivity of the material as well as provide an electrochemically 
efficient structure, whereby overpotentials that are required to initiate the dissolution $\left(\mathrm{U}_{1}\right)$ and precipitation $\left(\mathrm{U}_{2}\right)$ reactions are decreased. It should be noted that the tendencies observed for $U_{1}$ and $U_{2}$ are similar because these values are related to the overpotential in the reduction of $\mathrm{S}_{8}$ and HOPSs, respectively. In contrast, different behaviors were observed for $\mathrm{Q}_{1}$ and $\mathrm{Q}_{2}$, particularly under the highest current density, as shown in Figure $3 \mathrm{~g}$. The reaction kinetics for the formation of HOPSs is fast; thus, $Q_{1}$ is less affected by high current density. ${ }^{33}$ However, a significant decrease in $Q_{2}$ was observed at higher current density, which is attributed to the slow reduction due to the low electrical conductivity of LOPSs or limited reaction sites. The $\mathrm{Q}_{2} / \mathrm{Q}_{1}$ ratios in $\mathrm{S} / \mathrm{CB}$ were 2.36 and 1.27 , at $0.1 \mathrm{C}$ and $2 \mathrm{C}$, respectively, whereas higher $\mathrm{Q}_{2} / \mathrm{Q}_{1}$ ratios, 2.55 (at $0.1 \mathrm{C}$ ) and 1.75 (at $2 \mathrm{C}$ ), were achieved in GQDs-S/CB, which indicates that efficient utilization of sulfur occurred through the facile charge transfer and the high density of reaction sites.

\section{Post-mortem analysis}

Morphological evolution. SEM images of the anodes and cathodes (Supplementary Figures S11 and S12, respectively) were obtained from the GQDs-S/CB and S/CB electrodes after 20 cycles. Because of the formation of a thick solid electrolyte interphase (SEI) layer, the SEM images of the cathodes in Supplementary Figure S11 show flattened morphologies. Interestingly, homogenous surfaces could be observed in GQDs-S/CB, whereas segregation of sulfur was observed in the CB/ $\mathrm{S}$ electrode. This morphological difference was driven by the structural integrity of GQDs-S/CB. Because GQDs-S/CB electrodes could provide stable reaction sites during repeated cycling and preserve HOPSs in the vicinity of the electrode, the morphological change could be minimized. Moreover, continuous dissolution and precipitation of sulfur led to the significant change in the electrode morphology of $\mathrm{CB} / \mathrm{S}$, ultimately resulting in the segregation of sulfur on the surface of the electrode. Such loss of sulfur from the cathode was also observed in the anode. A clean surface was observed on the GQDs-S/ $\mathrm{CB}$ anode, whereas the $\mathrm{CB} / \mathrm{S}$ anode contained $\mathrm{S}$ and $\mathrm{Li}_{2} \mathrm{~S}$ particles on the surface, as confirmed by EDS and Raman spectroscopy (Supplementary Figure S12). As previously mentioned, these sulfur and $\mathrm{Li}_{2} \mathrm{~S}$ deposits resulted from the active materials lost from the cathode side during repeated cycling.

Surface modifications. To study the detailed mechanism through which the GQDs imparted high performance, the chemical bonding states of the S/CB and GQDs-S/CB electrodes harvested from the various states were characterized by XPS (Figure $4 \mathrm{a}-\mathrm{c}$ ). The $\mathrm{C} 1 \mathrm{~s}$ spectra of the as-prepared electrodes (Figure 4a) show peaks at $283.8 \mathrm{eV}$ and $284.5 \mathrm{eV}$ attributed to $\mathrm{sp}^{2}$ and $\mathrm{sp}^{3}$ hybridized carbons, respectively, whereas the peak at $285.3 \mathrm{eV}$ corresponds to $\mathrm{C}-\mathrm{S}$ bonding. ${ }^{34,35}$ The peak at $286.2 \mathrm{eV}$ is assigned to $\mathrm{C}-\mathrm{OH}$ bonding, which is more intense in GQDs-S/CB than in S/CB because the GQDs have a high density of $-\mathrm{OH}$ surface functional groups. The two peaks that correspond to carbonyl and carboxyl groups are located at 287.0 and $289.0 \mathrm{eV}$, respectively. The C $1 \mathrm{~s}$ spectra of the S/CB electrode harvested from both charged and discharged stages after the 20th cycle (Figure $4 \mathrm{~b}$ and $\mathrm{c}$ ) show a slight decrease and an increase in the intensity of the $\mathrm{C}-\mathrm{OH}(286.3 \mathrm{eV})$ and $\mathrm{C}-\mathrm{S}(285.3 \mathrm{eV})$ peaks, respectively. Although the GQDs-S/CB electrode showed a noticeable decrease in the hydroxyl peak $(286.2 \mathrm{eV})$, a C-S peak $(285.4 \mathrm{eV})$ became prominent in both the charged and discharged states after 20 cycles. The change in the bonding nature indicates that hydroxyl groups in the GQDs facilitated the formation of C-S bonds during cycling. The $\mathrm{C}-\mathrm{S}$ bonds generated in the GQDs-S/CB electrodes indicate that the GQDs exhibited sulfiphilic properties, enabling sulfur to be preserved in the vicinity of GQDs. Thus, the $\mathrm{Q}_{2} / \mathrm{Q}_{1}$ ratio was stable at $\sim 2.9$ even after 100 cycles. The $\mathrm{C}-\mathrm{F}_{2}$ peak at $\sim 291.0 \mathrm{eV}$ and the $\mathrm{C}_{-} \mathrm{F}_{3}$ peak at $\sim 293.0 \mathrm{eV}$ originated from the binder (polyvinylidene fluoride) and electrolyte salt (lithium bis(trifluoromethane) sulfonimide), respectively. ${ }^{36}$ The $S 2 p$ spectra of the electrodes harvested after 20 cycles also support the formation of $\mathrm{C}-\mathrm{S}$ bonding (Supplementary Figure S13). The C-S bonding peaks at $162.6 \mathrm{eV}$ are observed in both the S/CB and GQDs-S/CB electrodes. However, the intensity of $\mathrm{C}-\mathrm{S}$ bonding in the GQDs-S/CB electrode was higher than a

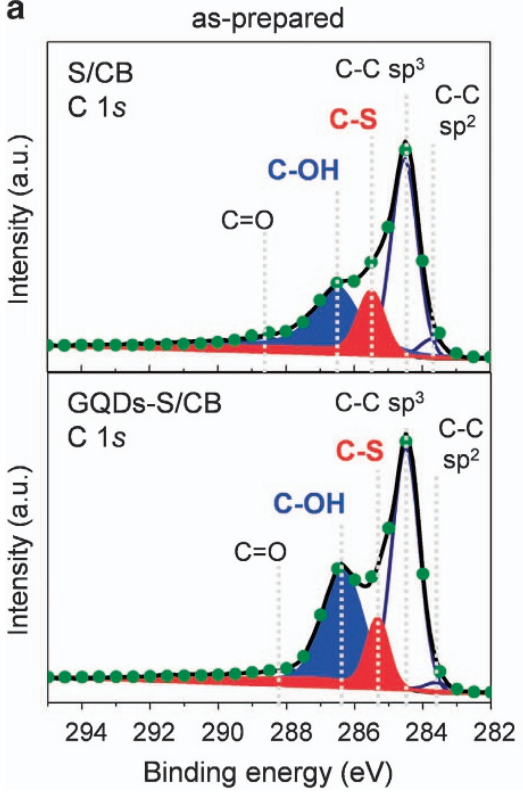

b

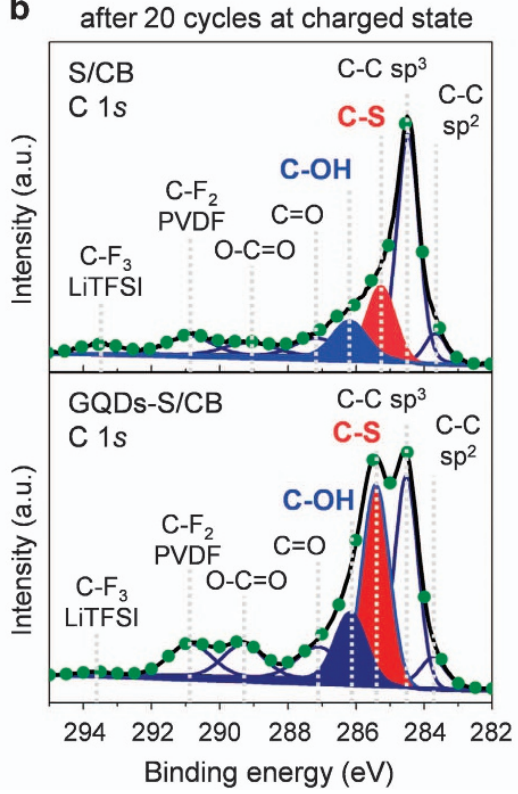

C after 20 cycles at discharged state

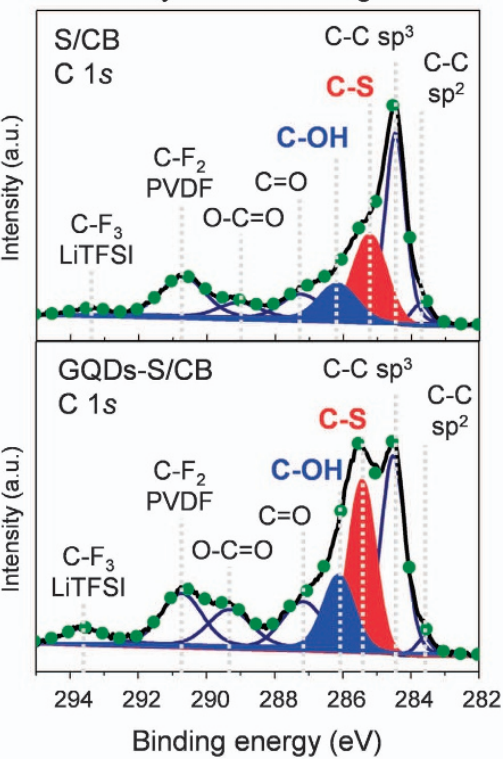

Figure 4 Post-mortem analysis of high-resolution X-ray photoelectron spectra (XPS). C $1 \mathrm{~s}$ high-resolution XPS spectra of the S/CB and GQDs-S/CB electrodes (a) before cycling and after 20 cycles in the (b) charged and (c) discharged state. Each spectrum was fitted with functions corresponding to different valencies of carbon and sulfur (navy solid line), and the sum of those fitted curves (green dots) is consistent with the raw data (black solid line). 
that in the S/CB electrode. ${ }^{29}$ The S-S bonding at $\sim 164.0 \mathrm{eV}$ is ascribed to the crystalline sulfur in the electrode. ${ }^{30}$ The S-S peak intensity of GQDs-S/CB was higher than that of S/CB because more elemental sulfur was reduced on the electrode. Adsorption processes prevented the irreversible loss of the active material into the electrolyte by the formation of nano-sized sulfur that bonded favorably to the GQDs, as discussed later. The peaks at $167.0 \mathrm{eV}$ and $\sim 170.0 \mathrm{eV}$ are attributed to sulfate, $\mathrm{SO}_{2}$, from LiTFSI and oxidized polysulfide species, $\mathrm{SO}_{3}$, respectively. ${ }^{36}$

\section{Theoretical modeling}

DFT calculations were performed to clarify the formation of C-S bonding between the GQDs and sulfur species. The calculation is based on the following reaction:

coronene_OH $+\mathrm{S}_{\mathrm{n}}{ }^{2-} \rightarrow\left(\text { coronene_S } \mathrm{S}_{\mathrm{n}}\right)^{-}+\mathrm{OH}^{-}(n=1,2,4,6,8)$

This model was used to represent the terminal edges of the GQDs, and we attached a hydroxyl group $(-\mathrm{OH})$ to one of the edges of the carbon atoms, 'coronene_OH'. ${ }^{37}$ A coronene is a polycyclic aromatic hydrocarbon comprising six peri-fused benzene rings with the chemical formula $\mathrm{C}_{24} \mathrm{H}_{12}$. Moreover, the coronene model is composed of small $\mathrm{sp}^{2}$ clusters and is isolated by $\mathrm{sp}^{3}$ carbon, which is close to individual GQDs without oxygen functional groups, and it has been previously employed as a reduced model of graphene for quantum calculations in lithium-sulfur battery studies. ${ }^{37,38}$ The relative energies calculated by DFT for the reactants and products indicate that replacing the terminal hydroxyl group by a sulfur dianion results in a lower energy state. The relative energies are shown in Figure 5, where it is clear that the energies of the product decrease when sulfur dianions are replaced with the terminal hydroxyl group. The lower energy of the products $\left(\mathrm{S}_{\mathrm{n}}{ }^{2-}, n=1,2,4\right.$ and 6) can provide a driving force for the reaction, thus making the formation of $\mathrm{C}-\mathrm{S}$ bonds favorable. However, the small sulfur dianions normally exist in the form of a solid crystal combined with lithium cations such that $\mathrm{Li}_{2} \mathrm{~S}$ that cannot easily participate in $\mathrm{C}-\mathrm{S}$ bonding. ${ }^{39}$ Furthermore, large sulfur dianion chains $(n>6)$ tend to disassemble into smaller chains. 39 Thus, it is speculated that the major participants in the reaction are $\mathrm{S}_{2}{ }^{2-}, \mathrm{S}_{4}{ }^{2-}$ and $\mathrm{S}_{6}{ }^{2-}$ ions. In addition, the same DFT calculation was performed for carboxyl group-terminated coronene (coronene_$\mathrm{COOH}$ ) (Supplementary Figure S14), which produced results similar to those obtained for the coronene_OH group. Our results highlight the crucial role of the formation of $\mathrm{C}-\mathrm{S}$ bonds through terminal oxygen functional groups present on the edge of GQDs.

Study of C-S bonding based on electrochemical cells using catholyte Intrinsic surface interactions at the interface between GQDs and $\mathrm{CB}$ were studied by electrochemical cycling with $\mathrm{Li}_{2} \mathrm{~S}_{8}$ catholyte. GQDs/CB and $\mathrm{CB}$ electrodes without sulfur were prepared and electrochemically cycled in $\mathrm{Li}_{2} \mathrm{~S}_{8}$ catholyte. The cycle retention of GQDs/CB exceeded $90 \%$ over 100 cycles, whereas CB exhibited $<80 \%$ capacity retention (Supplementary Figure S15c). After cycling

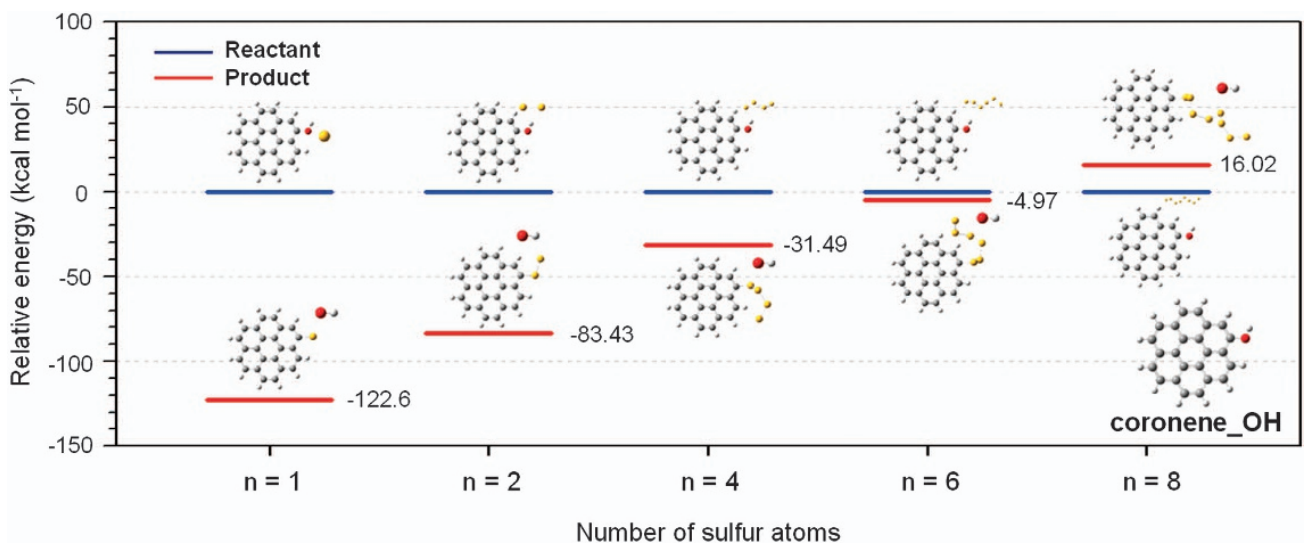

Figure 5 The relative energies for the reactants and products in the binding of polysulfides to GQDs. A plot of the relative energies for the reactants and products in the binding of polysulfides to GQDs versus the sulfur chain length. The functional groups on GQDs enhanced the binding of polysulfides to the carbon because of the substitution of $\mathrm{S}_{\mathrm{n}}{ }^{2-}$ for $-\mathrm{OH}(\mathrm{C}-\mathrm{OH})$. Yellow, red, white and gray represent $\mathrm{S}, \mathrm{O}, \mathrm{H}$ and $\mathrm{C}$ atoms, respectively.
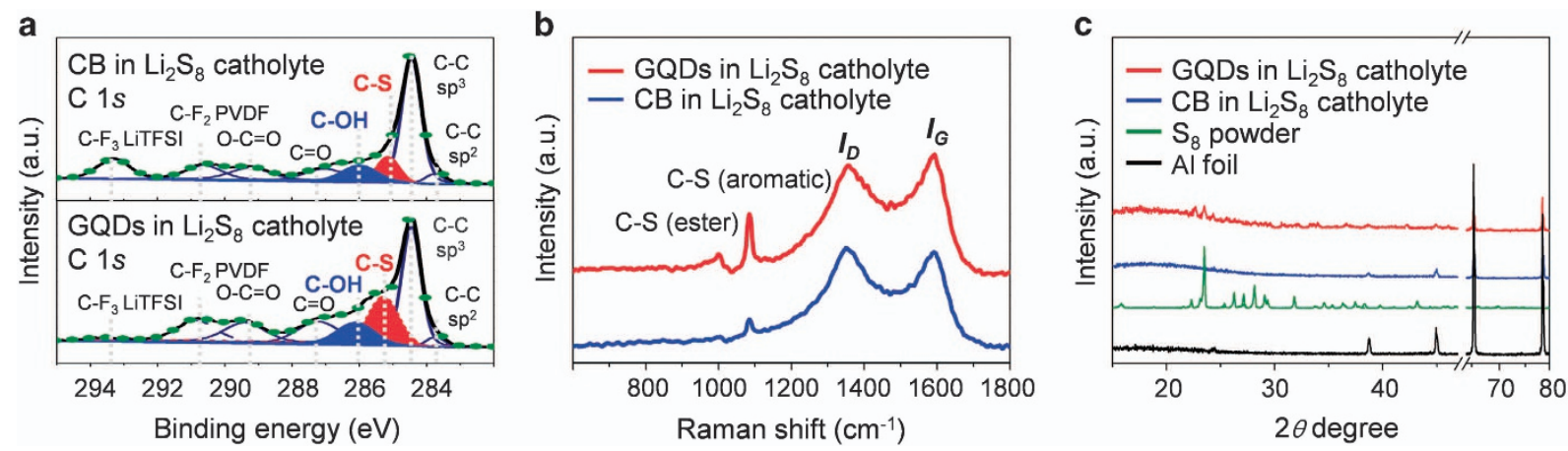

Figure 6 Post-mortem analysis of GQDs and CB electrode in $\mathrm{Li}_{2} \mathrm{~S}_{8}$ catholyte. (a) C $1 \mathrm{~s}$ high-resolution XPS spectra, (b) Raman spectra and (c) X-ray diffraction (XRD) spectra of $\mathrm{CB}$ and GQDs electrodes in $\mathrm{Li}_{2} \mathrm{~S}_{8}$ catholyte after 20 cycles in the charged state. Raman spectra showing $\mathrm{C}-\mathrm{S}$ (aromatic and ester) bond formation within the samples. 

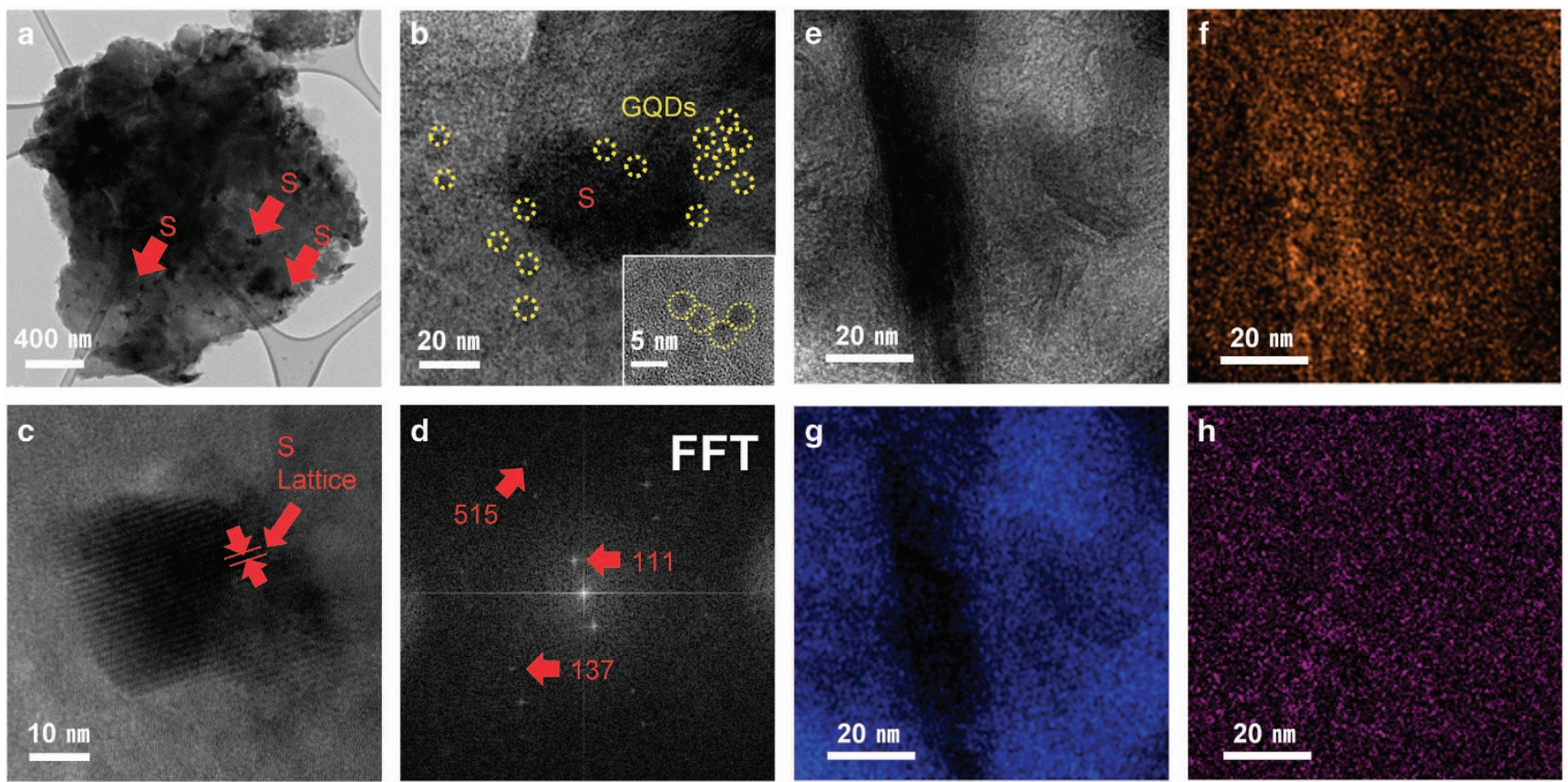

Figure 7 TEM and Scanning TEM images of nano-sized sulfur on GQDs electrode in $\mathrm{Li}_{2} \mathrm{~S}_{8}$ catholyte after 20 cycles in the charged state. (a) Low- and highmagnification images of nano-sized sulfur in GQD materials. The lump represents the GQDs electrode with nano-sized sulfur, and the small dark particles are nano-sized sulfur. (b) GQDs covered on nano-sized sulfur particle. (c) High-resolution transmission electron microscope (HRTEM) image showing the lattice fringes of the nano-sized sulfur and the GQDs. (d) The fast Fourier transform (FFT) of the original HRTEM image is $\mathbf{c}$ in the center of the filtered image. The two bright spots represent sulfur particles, and the other spot indicates the GQDs lattice plane. (e) STEM image of GQDs electrode in the catholyte after cycling. Electron energy loss spectroscopy (EELS) maps of (f) sulfur, (g) carbon and (h) oxygen in the GQDs/CB electrode.

the GQDs/CB electrode, the C $1 \mathrm{~s}$ and S 2p XPS spectra (Figure 6a, Supplementary Figure S15a and b) showed higher S-S and C-S peaks compared with those exhibited by CB. Furthermore, Raman peaks for C-S aromatic bonding at $1086 \mathrm{~cm}^{-1}$ and for C-S esteric bonds at $997 \mathrm{~cm}^{-1}$ were more intense for the GQDs/CB electrodes. ${ }^{40}$ The carbon peaks at $1590 \mathrm{~cm}^{-1}$ and $1350 \mathrm{~cm}^{-1}$ were assigned to the $G$ and the $\mathrm{D}$ bands of carbon, respectively (Figure $6 \mathrm{~b}$ ). X-ray diffraction of the GQDs/CB electrodes also confirmed the formation of nanosized crystalline sulfur (Figure 6c), which strongly indicates that PSs were adsorbed on the oxygen functional groups of GQDs.

The formation of nano-sized crystalline sulfur was also observed by TEM analysis. After 20 electrochemical cycles with $\mathrm{Li}_{2} \mathrm{~S}_{8}$ catholyte, only a small number of sulfur particles were observed on the $\mathrm{CB}$ electrode (Supplementary Figure S16), whereas many nano-sized sulfur particles can be observed on the GQD electrode in Figure $7 \mathrm{a}-\mathrm{d}$. Nano-sized sulfur particles were covered with GQDs, which was confirmed by lattice fringes corresponding to (111) planes. In addition, the indices of bright spots on the fast Fourier transform image indicate that sulfur was single-crystalline and crystallized in the orthorhombic structure of the alpha phase (JCPDS, No. 08-0247). ${ }^{41}$ The broad ring patterns in the fast Fourier transform image indicate the presence of multiple GQDs with different orientations in Supplementary Figure S17. The TEM-electron energy loss spectroscopy and SEM-EDS analyses of the GQDs also indicate that nanosized sulfur particles were adsorbed onto the GQDs (Supplementary Figure $\mathrm{S} 16 \mathrm{a}-\mathrm{d}, \mathrm{i}-\mathrm{l})$. In contrast, the $\mathrm{CB}$ electrode contained a low sulfur density (Supplementary Figure $\mathrm{S} 16 \mathrm{e}-\mathrm{h}, \mathrm{m}-\mathrm{p}$ ). This observation suggests that the GQDs exhibited sulfiphilic properties, leading to the preferred nucleation of sulfur on the GQDs. Furthermore, sulfur could easily be adsorbed/desorbed on the GQDs, as predicted by the aforementioned DFT calculation.

\section{CONCLUSIONS}

We designed GQDs-S/CB composites as high-performance cathode materials for the first time in Li-S batteries. The nano-sized GQDs induce a tightly packed structure via charge interaction with $\mathrm{S}$ and $\mathrm{CB}$, resulting in enhanced conductivity by shortened electron conduction paths. Furthermore, C-S bonding is generated in situ during battery operation, which originates from the oxygen-rich functional group at the edge of the GQDs. Thus, the loss of active materials into the electrolyte is minimized. The adsorption of nano-sized sulfur particles onto the GQD interfaces by $\mathrm{C}-\mathrm{S}$ bonding was predicted by DFT calculation and experimentally confirmed by various microscopic and spectroscopic analyses. The GQDs-S/CB composites significantly improve cycling and rate performances, and their electrochemical behavior could be understood by an in-depth analysis of discharge profiles. We believe that our results provide a new avenue for researchers to tailor the oxygen-rich functional groups of nano-sized carbon for application in Li-S batteries as well as various energy storage devices.

\section{CONFLICT OF INTEREST}

The authors declare no conflict of interest.

\section{ACKNOWLEDGEMENTS}

Y.-E.S. acknowledges financial support from the Institute for Basic Science (Grant No. IBS-R006-G1), Republic of Korea. B.H.H. acknowledges financial support from the Basic Science Research Program (2011-0017587) and the Global Research Lab (GRL) Program (2011-0021972) through the National Research Foundation of Korea funded by the Ministry of Science, ICT \& Future, Korea. C.K. and J.C. were supported as part of the Joint Center for Energy Storage Research (JCESR), an Energy Innovation Hub funded by the US Department of Energy, Office of Science, Basic Energy Sciences. X-ray 
diffraction analyses were supported by the Pohang Accelerator Laboratory (beamline 5A) and Korea I.T.S. Laboratory, Republic of Korea.

Author contributions: Y.-E.S. and B.H.H. conceived and supervised the project. J.P., J.M. and C.K. led the project. Y.-E.S., B.H.H., J.P., J.M. and C.K. wrote the manuscript, performed the laboratory experiments and analyzed the results. J.H.K. and J.P. assisted with materials analysis. E.L. and J.H. contributed to theoretical modeling. K.J.L. and S.-H.Y. assisted with electrochemical analysis. J.-H.S. and J.L. contributed to surface analysis. S.-P.C. and T.N. carried out TEM imaging. J.C., C.K. and J.P. prepared the manuscript, which incorporates critical input from all authors.

1 Goodenough, J. B. \& Park, K.-S. The Li-ion rechargeable battery: a perspective. J. Am. Chem. Soc. 135, 1167-1176 (2013).

2 Cabana, J., Monconduit, L., Larcher, D. \& Palacín, M. R. Beyond intercalation-based Li-ion batteries: the state of the art and challenges of electrode materials reacting through conversion reactions. Adv. Mater. 22, E170-E192 (2010).

3 Manthiram, A., Fu, Y. \& Su, Y.-S. Challenges and prospects of lithium-sulphur batteries. Acc. Chem. Res. 46, 1125-1134 (2013).

4 Chung, W. J., Griebel, J. J., Kim, E T., Yoon, H., Simmonds, A. G., Ji, H. J., Dirlam, P. T., Glass, R. S., Wie, J. J., Nguyen, N. A., Guralnick, B. W., Park, J., Somogyi, A., Theato, P., Mackay, M. E., Sung, Y. E., Char, K. \& Pyun, J. The use of elemental sulphur as an alternative feedstock for polymeric materials. Nat. Chem. 5, 518-524 (2013).

5 Bruce, P. G., Freunberger, S. A., Hardwick, L. J. \& Tarascon, J.-M. Li- $\mathrm{O}_{2}$ and Li-S batteries with high energy storage. Nat. Mater. 11, 19-29 (2012).

6 Choi, N.-S., Chen, Z., Freunberger, S. A., Ji, X., Sun, Y.-K., Amine, K., Yushin, G., Nazar, L. F., Cho, J. \& Bruce, P. G. Challenges facing lithium batteries and electrical double-layer capacitors capacitors. Angew. Chem. Int. Ed. 51, 9994-10024 (2012).

7 Ji, L., Aloni, S., Wang, L., Cairns, E. J. \& Zhang, U. Porous carbon nanofiber-sulphur composite electrodes for lithium/sulphur cells. Energy Environ. Sci. 4, 5053-5059 (2011).

8 Zhou, G., Pei, S., Li, L., Wang, D.-W., Wang, S., Huang, K., Yin, L. C., Li, F. \& Cheng, H. M. A graphene-pure-sulfur sandwich structure for ultrafast, long-life lithiumsulfur batteries. Adv. Mater. 26, 625-634 (2014).

$9 \mathrm{Ji}, \mathrm{X}$., Lee, K. T. \& Nazar, L. F. A Highly ordered nanostructured carbon-sulphur cathode for lithium-sulphur batteries. Nat. Mater. 8, 500-506 (2009).

10 Xin, S., Gu, L., Zhao, N.-H., Yin, Y.-X., Zhou, L.-J., Guo, Y.-G. \& Wan, L. J. Smaller sulphur molecules promise better lithium-sulphur batteries. J. Am. Chem. Soc. 134, 18510-18513 (2012).

11 Guo, J., Xu, Y. \& Wang, C. Sulphur-impregnated disordered carbon nanotubes cathode for lithium sulphur batteries. Nano Lett. 11, 4288-4294 (2011).

12 Wang, H., Yang, Y., Liang, Y., Robinson, J. T., Li, Y., Jackson, A., Cui, Y. \& Dai, H. Graphene-wrapped sulphur particles as a rechargeable lithium-sulphur battery cathode material with high capacity and cycling stability. Nano Lett. 11, 2644-2647 (2011)

13 Ji, L., Rao, M., Zheng, H., Zhang, L., Li, Y., Duan, W., Guo, J., Cairns, E. J. \& Zhang, Y. Graphene oxide as a sulphur immobilizer in high performance lithium/sulphur cells. J. Am. Chem. Soc. 133, 18522-18525 (2011).

$14 \mathrm{Zu}, \mathrm{C}$. \& Manthiram, A. Hydroxylated graphene-sulphur nanocomposites for high-rate lithium-sulphur batteries. Adv. Energy Mater. 3, 1008-1012 (2013).

15 Evers, S. \& Nazar, L. F. Graphene-enveloped sulphur in a one pot reaction: a cathode with good coulombic efficiency and high practical sulphur content. Chem. Commun. 48, 1233-1235 (2012).

16 Moon, J., Park, J., Jeon, C., Lee, J., Jo, I., Yu, S., Cho, S. P., Sung, Y. E. \& Hong, B. H. An electrochemical approach to graphene oxide coated sulphur for long cycle life. Nanoscale 7, 13249-13255 (2015).

$17 \mathrm{Fu}$, Y. \& Manthiram, A. Orthorhombic bipyramidal sulphur coated with polypyrrole nanolayers as a cathode material for lithium-sulfur batteries. J. Phys. Chem. C 116, 8910-8915 (2012)

18 Peng, J., Gao, W., Gupta, B. K., Liu, Z., Romero-Aburto, R., Ge, L., Song, L., Alemany, L. B., Zhan, X., Gao, G., Vithayathil, S. A., Kaipparettu, B. A., Marti, A. A., Hayashi, T., Zhu, J. J. \& Ajayan, P. M. Graphene quantum dots derived from carbon fibers. Nano Lett. 12, 844-846 (2012).

19 Ye, R., Xiang, C., Lin, J., Peng, Z., Huang, K., Yan, Z., Cook, N. P., Samuel, E. L., Hwang, C. C., Ruan, G., Ceriotti, G., Raji, A. R, Martí, A. A. \& Tour, J. M. Coal as an abundant source of graphene quantum dots. Nat. Commun. 4, 2943 (2013).

20 Ritter, K. A. \& Lyding, J. W. The influence of edge structure on the electronic properties of graphene quantum dots and nanoribbons. Nat. Mater. 8, 235-242 (2009).

21 Pan, D., Zhang, J., Li, Z. \& Wu, M. Hydrothermal route for cutting graphene sheets into blue-luminescent graphene quantum dots. Adv. Mater. 22, 734-738 (2010).

22 Konstantatos, G., Badioli, M., Gaudreau, L., Osmond, J., Bernechea, M., Arquer, F. P. G., Gatti, F. \& Koppens, F. H. Hybrid graphene-quantum dot phototransistors with ultrahigh gain. Nat. Nanotechnol. 7, 363-368 (2012).
23 Chao, D., Zhu, C., Xia, X., Liu, J., Zhang, X., Wang, J., Liang, P., Lin, J., Zhang, H., Shen, Z. X. \& Fan, H. J. Graphene quantum dots coated $\mathrm{VO}_{2}$ arrays for highly durable electrodes for $\mathrm{Li}$ and $\mathrm{Na}$ ion batteries. Nano Lett. 15, 565-573 (2015).

24 Zhu, C., Chao, D., Sun, J., Bacho, L. M., Fan, Z., Ng, C. F., Xia, X., Huang, H., Zhang, H., Shen, Z. X., Ding, G. \& Fan, H. J. Enhanced lithium storage performance of CuO nanowires by coating of graphene quantum dots. Adv. Mater. Interfaces 2, 1400499 (2015).

25 Stephens, P. J., Devlin, F. J., Chabalowski, C. F. \& Frisch, M. J. Ab Initio calculation of vibrational absorption and circular dichroism spectra using density functional force fields. J. Phys. Chem. 98, 11623-11627 (1994).

26 Frisch, M. J., Trucks, G. W., Schlegel, H. B., Scuseria, G. E., Robb, M. A., Cheeseman, J. R., Scalmani, G., Barone, V., Mennucci, B., Petersson, G. A., Nakatsuji, H., Caricato, M., Li, X., Hratchian, H. P., Izmaylov, A. F., Bloino, J., Zheng, G., Sonnenberg, J. L., Hada, M., Ehara, M., Toyota, K., Fukuda, R., Hasegawa, J., Ishida, M., Nakajima, T., Honda, Y., Kitao, O., Nakai, H., Vreven, T., Montgomery, J. A., Jr., Peralta, J. E., Ogliaro, F., Bearpark, M., Heyd, J. J., Brothers, E., Kudin, K. N., Staroverov, V. N., Kobayashi, R., Normand, J., Raghavachari, K., Rendell, A., Burant, J. C., Iyengar, S. S., Tomasi, J., Cossi, M., Rega, N., Millam, J. M., Klene, M., Knox, J. E., Cross, J. B., Bakken, V., Adamo, C., Jaramillo, J., Gomperts, R., Stratmann, R. E., Yazyev, O., Austin, A. J., Cammi, R., Pomelli, C., Ochterski, J. W., Martin, R. L., Morokuma, K., Zakrzewski, V. G., Voth, G. A., Salvador, P., Dannenberg, J. J., Dapprich, S., Daniels, A. D., Farkas, Ö., Foresman, J. B., Ortiz, J. V., Cioslowski, J. \& Fox, D. J. Gaussian 09 (Gaussian, Inc.: Wallingford CT, 2009).

27 Acik, M., Lee, G., Mattevi, C., Pirkle, A., Wallace, R. M., Chhowalla, M., Cho, K. \& Chabal, Y. The role of oxygen during thermal reduction of graphene oxide studied by infrared absorption spectroscopy. J. Phys. Chem. C 115, 19761-19781 (2011).

28 Gokus, T., Nair, R. R., Bonetti, A., Bohmler, M., Lombardo, A., Noboselov, K. S., Geim, A. K., Ferrari, A. C. \& Hartschuh, A. Making graphene luminescent by oxygen plasma treatment. ACS Nano 3, 3963-3968 (2009).

29 Yeon, J.-T., Jang, J.-Y., Han, J.-G., Cho, J., Lee, K. T. \& Choi, N.-S. Raman spectroscopy and X-ray diffraction studies of sulphur composite electrodes during discharge and charge. J. Electrochem. Soc. 159, A1308-A1314 (2012).

30 Moulder, J. F., Stickle, W. F., Sobol, P. E. \& Bomben, K. D. Handbook of X-ray Photoelectron, (Spectroscopy, Physical Electronics, Inc., 1995).

31 Su, Y.-S., Fu, Y., Cochell, T. \& Manthiram, A. A strategic approach to recharging lithium-sulphur batteries for long cycle life. Nat. Commun. 4, 2985-2992 (2013).

32 Deng, Z., Zhang, Z., Lai, Y., Liu, J., Li, J. \& Liu, Y. Electrochemical impedance spectroscopy study of a lithium/sulphur battery: modelling and analysis of capacity fading. J. Electrochem. Soc. 4, A553-A558 (2013).

33 Bruckner, J., Soren, T., Grossmann, H. T., Dorfler, S., Althues, H. \& Kaskel, S. Lithium sulphur batteries: influence of C-rate, amount of electrolyte and sulphur loading on cycle performance. J. Power Sources 268, 82-87 (2014).

34 Kaciulis, S. Spectroscopy of carbon: from diamond to nitride films. Surf. Interface Anal. 44, 1155-1161 (2012).

35 Kummer, K., Vyalikh, D. V., Gavrila, G., Kade, A., Weigel-Jech, M., Mertig, M. \& Molodtsov, S. L. High-resolution photoelectron spectroscopy of self-assembled mercaptohexanol monolayers on gold surfaces. J. Electron Spectrosc. Relat. Phenom. 163, 59-64 (2008).

36 Song, J., Lee, S. J., Kim, Y., Kim, S.-S., Lee, K. T. \& Choi, N.-S. Thermal reactions of lithiated and delithiated sulphur electrodes in lithium-sulfur batteries. ECS Electrochem. Lett. 3, A26-A29 (2014).

37 Song, J., Xu, T., Gordin, M. L., Zhu, P., Lv, D., Jiang, Y.-B., Duan, Y. \& Wang, D. Nitrogen-doped mesoporous carbon promoted chemical adsorption of sulphur and fabrication of high-areal-capacity sulphur cathode with exceptional cycling stability for lithium-sulphur batteries. Adv. Funct. Mater. 24, 1243-1250 (2014).

38 Sk, M. A., Ananthanarayanan, A., Huang, L., Lim, K. H. \& Chen, P. Revealing the tunable photoluminescence properties of graphene quantum dots. J. Mater. Chem. C 2, 6954-6960 (2014)

39 Berghof, V., Sommerfeld, T. \& Cederbaum, L. S. Sulfur cluster dianions. J. Phys. Chem. A 102, 5100-5105 (1998).

40 Socrates, G. Infrared and Raman characteristic group frequencies tables and charts: Sulphur and Selenium compounds. 3rd edn Ch.16 (John Wiley \& Sons Ltd, 2001).

41 Abrahams, S. C. The crystal and molecular structure of orthorhombic sulphur. Acta Crystallogr. 8, 661-671 (1955).

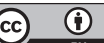

This work is licensed under a Creative Commons Attribution 4.0 International License. The images or other third party material in this article are included in the article's Creative Commons license, unless indicated otherwise in the credit line; if the material is not included under the Creative Commons license, users will need to obtain permission from the license holder to reproduce the material. To view a copy of this license, visit http:// creativecommons.org/licenses/by/4.0/ 